\title{
The musicalization of graphic narratives and P. Craig Russell's graphic novel operas, The Magic Flute and Salomé
}

Victoria Addis, University of St Andrews

How is music represented in graphic narratives? What formal advantages do they have for realizing musical representation? And to what extent can they be 'musicalized'? This article examines several formal similarities between music, and comics and graphic novels, which indicate a strong potential for the musicalization of the medium, and explores tentative examples of already musicalized graphic narratives in the form of P. Craig Russell's graphic novel operas, The Magic Flute (1989-90) and Salomé (1986). The term 'musicalization' comes from Werner Wolf's, The Musicalization of Fiction (1999). In this book, Wolf proposes the musicalized text as one that has an intentional and sustained connection to music and musical form, which moves beyond the purely diegetic or incidental (1999: 34). While comics directly representing music have achieved some measure of popular success; the rock comics published by Rock N'Roll Comics (Loren 1989-93) and Hard Rock Comics (Various 1992-93), blues comics such as Rob Vollmar's Bluesman (2008) and Robert Crumb's Patton (1984), and of course the graphic novel operas with which this article will be concerned, the formal relationship between music and comics has so far received little critical attention. Existing scholarship and other commentary has either tended to view music in comics as nothing more than a 'soundtrack' (Godek 2006: n.pag.), and has therefore focused largely on the simple presence of musical notation in a work (Whitted 2011; Brown 2013), or has been concerned with analysing the representation of music within a specific graphic narrative or narratives (Peters 2013). This article seeks to make a meaningful intervention into this gap in scholarship by examining the formal similarities between music and comics on a conceptual 
level, and by demonstrating through use of examples, the ways in which these similarities have been exploited in practice.

\section{The musicalization of graphic narratives}

A foundational notion in comics scholarship is that of the ImageText, which was suggested by W. J. T. Mitchell in his influential essay 'Beyond comparison'. The ImageText posits an equivalence between text and image in graphic narratives, merging them together to form a unified comics language (Mitchell 2009: 129). The idea of comics as a kind of language, which can be broken down into semiotic units, has taken hold in the field, encouraging discussion of the page, the panel, and the line, in terms of their semiotic function. The implications of this for the musicalization of graphic narratives lie in the parallels that can be drawn between the units of comics language, and of musical language. As Werner Wolf states, '[t]he view that music may now be analysed in semiotic terms and thereby be compared to (literary) language is, by now, in spite of resistance by some critics [...] widely accepted' (1999: 15). Just as comics scholars can discuss the page and the panel as structurally relevant units, so the musicologist can discuss the phrase and the bar. The parallels between these two forms offer a template for the musicalization of graphic narratives, and one that has been alluded to by comics writers and artists who view comics panels as 'beats', and the comics grid 'as a metronome giving measure to the narrative's shifts and fits' (Spiegelman 2004: n.pag.). The most crude and literal examples of this parallel can be found in representations of guitar tablature and musical staves running across panels, such as in Scott Pilgrim (O'Malley 2004: 10) and the 'Vicious cabaret' in $V$ for Vendetta (Moore 2005: 89). That graphic narratives are able to represent sheet music and other forms of musical notation across their visual sequence, suggests a sense of parity between music and the comics grid. These examples would not however satisfy the criteria for 'musicalized' narratives, as musical notation itself is already a signifier for actualized 
music, and such a straightforward representation does not offer any significant engagement with the formal features of comics.

In a recent revaluation of comics theory, Hannah Miodrag has rejected the idea of comics as a kind of language beholden to a single semiotic system. Miodrag argues that while words can be broken down into smaller signifying units (e.g. syllables or phonemes), an image cannot. Using Umberto Eco's example from A Theory of Semiotics ([1975] 1976), which explains that a semicircle and a dot may appear as an eye and a mouth in one image, but may be taken as a grape and a fruit bowl in another, Miodrag argues that meaning in visual art is found in the context of the iteration, not in the abstract form. In Saussurean terms, images operate as parole and not langue (Miodrag 2013: 9). The problematics of the visual unit on this micro level offer up another interesting parallel with music, as graphic narratives may be said to differ from language in the same way that music does. Like lines in a drawing, 'a note has no meaning in itself, but gains whatever meaning it has by being put in a series of other notes' (Wolf 1999: 24). This connection is deepened when we move beyond the line drawings considered by Eco and Miodrag to examine colour.

Individual colours, like individual notes, are not always experienced in the same way. The tone and feel of any individual colour relies heavily on its context. As the artist Josef Albers stated in his influential work Interaction of Color: ' $[\mathrm{c}]$ olors themselves are in continuous flux, constantly related to changing neighbours and changing conditions' ([1963] 2006: 5). On the most basic level, this can be seen in the different effects created by palettes of complementary or analogous colours (colours that are opposite, or next to each other on the colour wheel). Where analogous colours can create an almost monochromatic effect centred on the dominant colour, complementary colours appear more vibrant when paired together. In this sense, therefore, musical notation, and the colour within an image, or a collection of images, can be said to share certain properties. Not only do individual colours 
and individual notes react in similar ways to their surrounding context, there are also parallels in the ways these contexts can be manipulated for effect within the different media. As B. M. Galeyev has observed, 'there are generalized music-visual associations between tempo and visual transformations, as well as between major and minor key change and a change in lighting' (2007: 288). The problems with relying on these parallels for theorizing a musicalized graphic narrative are, however, all too apparent. Most importantly, these similarities focus solely on the visual aspect of comics, and not on the medium as a whole. Furthermore, recognizing that comics and music differ from language in the same way (in that neither are so easily broken down into meaningful units), does not immediately mean that they correlate any more with each other. Taken in addition to several other factors, however, these observations provide a starting point for considering the status of music and comics as sister arts.

One of the key similarities between music and graphic narratives, over and above the connections posited between music and fiction, is the relationship between musical polyphony and the simultaneity of graphic narratives. The biggest point of departure between music and fiction that Werner Wolf identifies is the restriction of fiction to linear sequence in comparison to the phenomenon of polyphony in music:

in most cases a piece of (Western) music does not only consist of one sequence of sound, but often of several simultaneous sequences, while a work of (narrative) literature is made out of one linear sequence of words only. (1999: 20)

Graphic narratives are not restricted to linearity in the same way as other fictions. While comic book artists and theorists like Scott McCloud in Understanding Comics ([1993] 2001) and Will Eisner in Comics and Sequential Art (1985), focus on the idea of comics as 'sequential art', a definition that prioritizes the movement of the narrative across the panels from left to right, there is more to a comics page than this surface level sequentiality. When 
as readers we take in the page, our eyes do not, as the term 'sequential art' might imply, head immediately for the top left and follow the narrative through the panels. Instead, we may take in the whole page at once, or later panels that draw our attention with their size, content or colour palette. In theorizing non-sequential reading, two key terms have emerged: the 'tabular' (Fresnault-Deruelle 1976) and the translinear. The translinear, as defined by Thierry Groensteen in The System of Comics, is the idea that there is 'a dechronologized mode, that of the collection, of the panoptical spread and of coexistence, considering the possibility of translinear relations and plurivectoral courses' (2006: 146-47). The potential for nonsequential readings introduces the idea of simultaneity into the experience of reading graphic narratives.

A double page spread from Neil Gaiman's Sandman Overture (2014: 10-11) exemplifies this simultaneity through its depiction of concurrent multiple manifestations of Dream's selves. As the diminutive figure of the human Dream folds his arms in the centre of the scene, proclaiming, '[a]m I always like this?' (2014: 10), his multiple selves chatter and bicker around him in panels that serve as magnifying lenses, picking out elements of the larger single scene with all but scant regard for the traditional grid. Amongst this plurality of voices, we find other human Dreams interacting with or reacting to his other selves. A sequential reading of this page may take us through the reverse ' $S$ ' shape of the human Dream's path through the gathering, or through the magnified panels, but before we can think sequentially, we are encouraged to view this scene as a whole. It is in this whole that the simultaneity exists most completely, both in the polyphony of the many voices, and in the temporal simultaneity of the gathering as a single captured moment, and as a continuous present. In Alan Moore and Dave Gibbons' Watchmen (2013), the character of Dr Manhattan embodies this simultaneity in his increasing omnipotence. His mutation takes him from ordinary human to an almost God-like figure, 'he lives in the past, the present and the future 
simultaneously: everything is always happening at once for him' (Carney 2006: 14). This is reflected in a single page, wherein we experience many possible times at once through the recurring image of a photograph in different spatial and temporal locations (Moore and Gibbons 2013: 111). This use of repetition signals another correlation between graphic narratives and music: what Werner Wolf describes in music as, 'the possibility of creating potentially meaningful recurrences on various levels' (1999: 17), or more simply, modulations and motifs.

When we speak of meaning in instrumental music, it is not necessarily in the same sense as when we refer to meaning in, for example, a piece of narrative fiction, yet there are ways in which music can be said to produce meaning. Indeed, it is from this very premise that the musicalization of fiction came to be theorized:

the very fact that music can have meaning permits something which has been radically contested [...], the at least partial translatability of music, or elements of it, into another medium $[\ldots]$ the very phenomenon of the musicalization of fiction (Wolf 1999: 33, original emphasis).

The ways in which music can have meaning have been identified as the 'expressive meaning' found in the feelings evoked by certain musical forms and techniques, the meanings taken from music's relationship to wider culture, both in terms of 'culturally assigned' meanings and references to culture itself, and, predominantly, self-referential meanings emerging from formal relations within the composition (Wolf 1999: 23). These 'formal relations' emerge through structures of repetition, which can either be a series of direct repetitions, otherwise known as motifs or repetitions which are slightly altered between iterations, which are described as modulations. These interrelationships within a piece of music operate in a comparable fashion to similar 'parallelisms, variations, contrasts, or foregrounded variations' in graphic narratives (1999: 17). In Watchmen, for example, the single image of Dr Manhattan's photograph is repeated several times in the space of just one page. In a manner 
similar to musical modulation, this image takes on different meanings as it appears in the context of different panels. The photograph Dr Manhattan holds in his hand while in selfimposed exile on Mars carries a weight of sadness, which that same photograph does not have in the moment it was first pinned on the noticeboard. This kind of repetition is not so easily achieved in literature. As Wolf asserts:

music demands far more repetition than poetry can tolerate (let alone narrative literature, in which verbatim repetitions, which are possible in the refrains of lyrics, are next to impossible - unless they occur in experimental, 'lyricalized' texts. (1999: 35)

Graphic narratives have none of these limitations, and can repeat and layer images with all of the freedoms of music. The extent to which comics can become layered in repetitions is apparent in P. Craig Russell's adaptation of Richard Wagner's The Ring of the Nibelung, which replaces Wagner's musical leitmotifs with visual ones, namely water, the tree, the sword, and Odin's eye (2014: 76). The consistent repetition of these images across Russell's adaptation demonstrates that graphic narratives are not as limited as purely linguistic narratives in their use of this technique.

Another key correlative between music and graphic narrative, this time shared also with fiction, is rhythm. Rhythm is apparent in the metrics of literature (including the literary aspects of graphic narratives), and also in the idea of panels as 'beats'. Viewing the traditional grid as akin to musical 'common time' of 4/4 (four beats per bar), we can see how an increased number of panels speeds up the readers' sense of time just as fewer panels slows it down, and how other subtle variances in the structure (the relative size of panels, certain stylistic choices) alter our perception, and break up the visual monotony of the traditionally structured grid. As Joseph Witek states, '[1]ike slight variations in poetic meter and rhyme, even this relatively small change in the regularity of the grid mitigates the visual sing-song of identically shaped and sized panels' (2009: 153). These techniques are utilized to great effect 
in Alan Moore and Dave Gibbons' Watchmen, which is almost entirely constructed using the traditional grid, and subtle variations on it. For example, at the close of one of the book's 'chapters', a large, completely black panel in the bottom third of the grid disrupts the regular pattern of the preceding pages to focus in on the all-consuming darkness of the Rorschach blot (Moore and Gibbons 2013: 206). This disruption momentarily slows the reading time, emphasising the visual abyss over the textual 'abyss' referenced in the Nietzsche quote, which itself is squashed into the final, thinner panel that follows. After the extended pause of a wide all-black panel, this thin panel with its vertically stacked text has the effect of a final drop or rapid descent into nothing as the section comes to a close. A similar manipulation of time is seen in music, through the admittedly much more limited technique of rubato; the variation of the speed of music in performance.

The final sense in which music and graphic narratives can be said to correspond is through their representations of dissonance and harmony, which in graphic narratives can be shown, for example, through visual contrasts of colour and style. The majority of graphic narratives display a sense of harmony, usually selecting a small range of colours and/or one consistent artistic style. While this may vary across the narrative, the harmony of the individual page tends to persist, with exceptions for instances of dramatic emphasis or effect. This can be seen in the pages of Watchmen that show Dr Manhattan creating a new world on Mars (Moore and Gibbons 2013: 136-38). The colours are rendered consistently in blues and pinks, constructing a sense of harmonious continuity, until a sudden yellow interrupts, rupturing the present with details and emotions from the past, which bring with them a sense of inevitability and doom: the sense that 'it always will be too late' (2013: 138). Dissonance can also be achieved through contrasting artistic styles occupying the same page, or even the same panel, as in the frenzied depiction of the dancers of 'The Rite of Spring' in Melinda Gebbie's artwork for Alan Moore's Lost Girls (2006: 104), and through things such as the 
arrangement of the panels themselves, the positioning, colouring and shape of the panel outlines and guttering, and the 'grammatextuality' of the page: '[ $t$ ]he form of the lettering, the configuration of the words in the speech balloons and the insertions of these balloons in the panels, the presence of letters and other written symbols' (Baetens and Frey 2015: 153). These grammatextual techniques, a staple of the so-called 'baroque' style of comics of the 1940s, also include some of the first instances of 'sound' in comics, in the now clichéd 'BAM! POW!' of these early works.

In spite of these visual sound effects or approximations of sound, which we find in the BOOM! of an explosion, the ZAP! of a laser, or the numerous squiggles and lines suggesting a ringing bell or a blaring horn, the "“silence" of comics' (Lefèvre 2007: 4) has, in its literal sense, been absolute. With the advent of new technologies, however, this silence has been broken. Web comics, such as Kean Soo's Exit Music, and Colleen Macisaac's Music Comics, for example, have included $\mathrm{mp} 3 \mathrm{~s}$ to act as an accompaniment to the reading experience. Tym Godek has discussed this particular use of technology, along with a series of future possibilities for the technological integration of actualized music in comics in his brief article, 'Music and comics: Two great tastes that taste great together?' (2006). What emerges from this examination is the idea that, 'the closer we get to true music/narrative integration the further we stray from comics' (Godek 2006: n.pag.). The integration of sound technologies into comics, therefore, appears to run counter to the tenets of a musicalized narrative. Actualized sound is not necessary for a text to become musicalized, and may in fact move it further away from that aim. Experimentation with these sound technologies is however an interesting way to test the limits of comics as a medium with the potential to produce innovative and exciting work, and if nothing else, serves to further underpin the extent of music's appeal to comics writers and artists. 
These several interconnections between musical form and graphic narratives lead me to conclude that, as Werner Wolf suggests of music and fiction, music and graphic narratives are 'sister arts', able to be profitably discussed in relation to each other. The potential for the musicalization of graphic narratives is an exciting avenue that reaches beyond that same potential that Werner Wolf elucidates for fiction, as graphic narratives are free from many of the limitations outlined in Wolf's study, while also bearing the same potentialities in terms of their literary aspect. Through their polyphonic simultaneity, their potential for sustained visual motifs and modulations, and the harmonies and dissonances of the page, graphic narratives display a natural affinity to the forms and structures of music, and it is for this reason perhaps, that music has found expression or representation in such a number of graphic narratives, including those to which I now turn: the graphic novel operas of P. Craig Russell.

\section{P. Craig Russell's graphic novel operas}

P. Craig Russell's Library of Opera Adaptations is a three-volume collection of classic operas adapted into graphic novel form. The success of these adaptations is not just in their communication of classic operas into an accessible form, but as artworks in themselves. Russell makes full use of the graphic novel as a medium to capture the imaginative scope of the works he is adapting, and makes artistic and interpretive decisions that bring out the inherent musicality of the comics page. His adaptations are written using English language translations of the original libretti, and present an exciting pathway into analysing some of the potentialities for the musicalization of graphic narratives. The adaptations I will focus on here will be The Magic Flute and Salomé.

In A Theory of Adaptation, Linda Hutcheon discusses the popular critical opinion of adaptations as secondary and inferior derivations of their source text (2013: 4). The inferiority of an adaptation to an original is in large part related to the form into which the 
source text is being adapted. As Hutcheon notes, 'it does seem to be more or less acceptable to adapt Romeo and Juliet into a respected high art form, like an opera or a ballet, but not to make it into a movie' (2013: 3). P. Craig Russell's opera adaptations, then, go against the grain of such notions of acceptability, adapting a 'high' art into a much less established form. In his 1991 interview with Comics Journal, Russell said of his work that: 'it has to work as a comic, not just an illustrated book' (1991: 54). This willingness to explore and utilize the comics medium, and to take liberties with the source material in order to produce the best interpretation and adaptation rather than the best likeness is what marks out Russell's work against other graphic adaptations, such as the Classics Illustrated series of literary works, which often held the subject matter in too great a reverence to properly adapt it. Mozart's The Magic Flute is an excellent example of a of multiply adapted source text. It has been successfully set in a variety of time periods and locations, from fairy tale and fantasy worlds to the trenches of the First World War. In film and stage adaptations, the music of the opera is preserved regardless of how much the story may get manipulated, but for the graphic novel, it is the music itself that has to be adapted into the visual/textual stream. In Russell's The Magic Flute, the music of the opera is at times experienced obliquely through the pacing and rhythm of the panels, and through the arrangement of images on the page. While the panels do not represent an exact recreation of the tempo of the piece in visual form, there are significant points at which the graphic narrative can be said to have become 'musicalized' or to have taken on features of the musical source material.

The Magic Flute is a simple story of light versus dark; Sarastro representing the light and the Queen of the Night, the dark. Russell captures this dichotomy through the alternating colour palettes of yellows, reds and oranges for the 'good' characters, and dark blues and purples for the Queen of the Night. The narrative of the opera follows the young hero Tamino, as he is tricked by the Queen of the Night into believing that the 'evil' Sarastro has 
kidnapped her daughter, the beautiful Pamina. Along with the comedic Papageno, bird catcher to the Queen, Tamino sets off to rescue the girl. He is given a magic flute, and Papageno some magic bells to aid them in their quest. Russell's adaptation follows the plot of the opera closely, and draws out its comedic and dramatic elements through medium specific representations. Like the opera, it opens with the overture of Tamino's nightmare, represented in a series of six-panel pages, separated by thick black guttering. These snapshot images capture the fragmented nature of Tamino's dreaming, and offer the opportunity for visual comedy in his rude awakening by Papageno when the bird catcher interrupts the nightmarish dream panels with calls of 'Hey', 'Hey Buddy' (Russell 2003: 11, 12). The comedic possibilities of Tamino's naïve chivalry are likewise exploited. The boy exclaims with one hand raised in the air, the other on his chest: 'I will rescue her though all of hell should conspire [...]' before being cut off by the Queen of the Night: 'Indeed my son, indeed [...]' (2003: 18). Tamino's high ideals, and his conformity to strict codes of conduct are reflected in the large, uniform font of his speech, and the square speech bubble that surrounds it. The large, bold 'Indeed' with which the Queen of the Night interrupts forces the curve of its rounder speech bubble out into a jagged edge, to give a sense of the volume of the interruption, with the font then decreasing into standard size. Russell's use of these mediumspecific techniques, representing the word as image, exemplifies the ways in which his adaptations go beyond simple illustration.

The most famous piece within The Magic Flute is the aria of the Queen of the Night. In Figure 1, we can see that this aria retains some of its dramatic impact in Russell's rendering. The Queen enfolds the story panels in her open arms as she makes her murderous request of Pamina, her figure reaching from the top to bottom of the page. The close up of her manic face at centre of the bottom panel contrasts sharply with the diminished form of the girl on the following page, serving to emphasise the power dynamic between mother and 
daughter that is so palpable in the drama of the aria. While the music itself is absent in these pages, the atmosphere of the production as a whole is fully realized. Another favourite section of the opera, the meeting between Papagano and Papagena, presents more of an opportunity to discuss musicalization. The Papageno/Papagena duet is not replicated exactly in the text for the obvious reason that panels full of their repeated names would not be enjoyable to read, thereby demonstrating Werner Wolf's assertions about the limits of repetition in literature (1999: 19). This linguistic play is, however, hinted at earlier in the text of the adaptation: 'Pa...Papa...Papagena!' (Russell 2003: 85). In spite of the limitations of the text, the visual elements manage to convey the staccato rhythm and alternation at the heart of the music (Figure 2). Russell emphasises the comedic, slapstick elements of their interaction by breaking up the page in a very different way to the rest of the story, leaving a significant amount of white space. This white space hints at the missing parts of the duet's text, and highlights the quirks of these characters, living outside the panels as well as in them. The alternating pattern of the characters of Papagano and Papagena on the page reflects the rapid back and forth of the opera's duet, and having them both 'in-shot', occupying the same panel, underlines their close relationship; as their names suggest, two halves of a whole (Russell 2003: 103). To appreciate the playful back and forth of these two characters, the staccato rhythm, and the personality of these colourfully drawn figures requires no foreknowledge of the music itself, though a familiarity with the opera does serve to enhance the experience of this scene for the reader. 


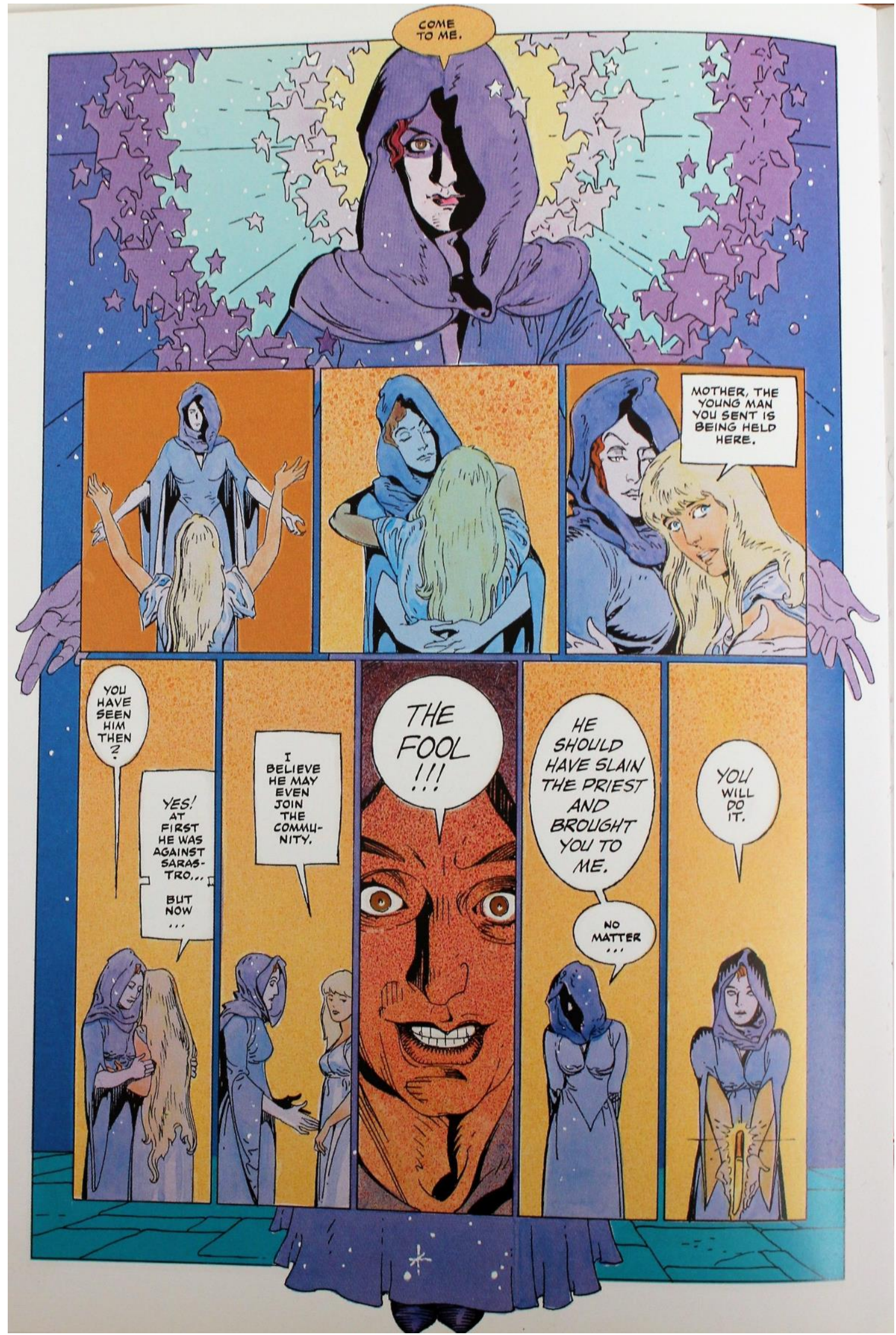

Figure 1: The aria of the Queen of the Night, The Magic Flute, The P. Craig Russell Library of Opera Adaptations Vol. 1, page 58. (C) 1990 P. Craig Russell. Available from NBM Graphic Novels: www.nbmpub.com. 


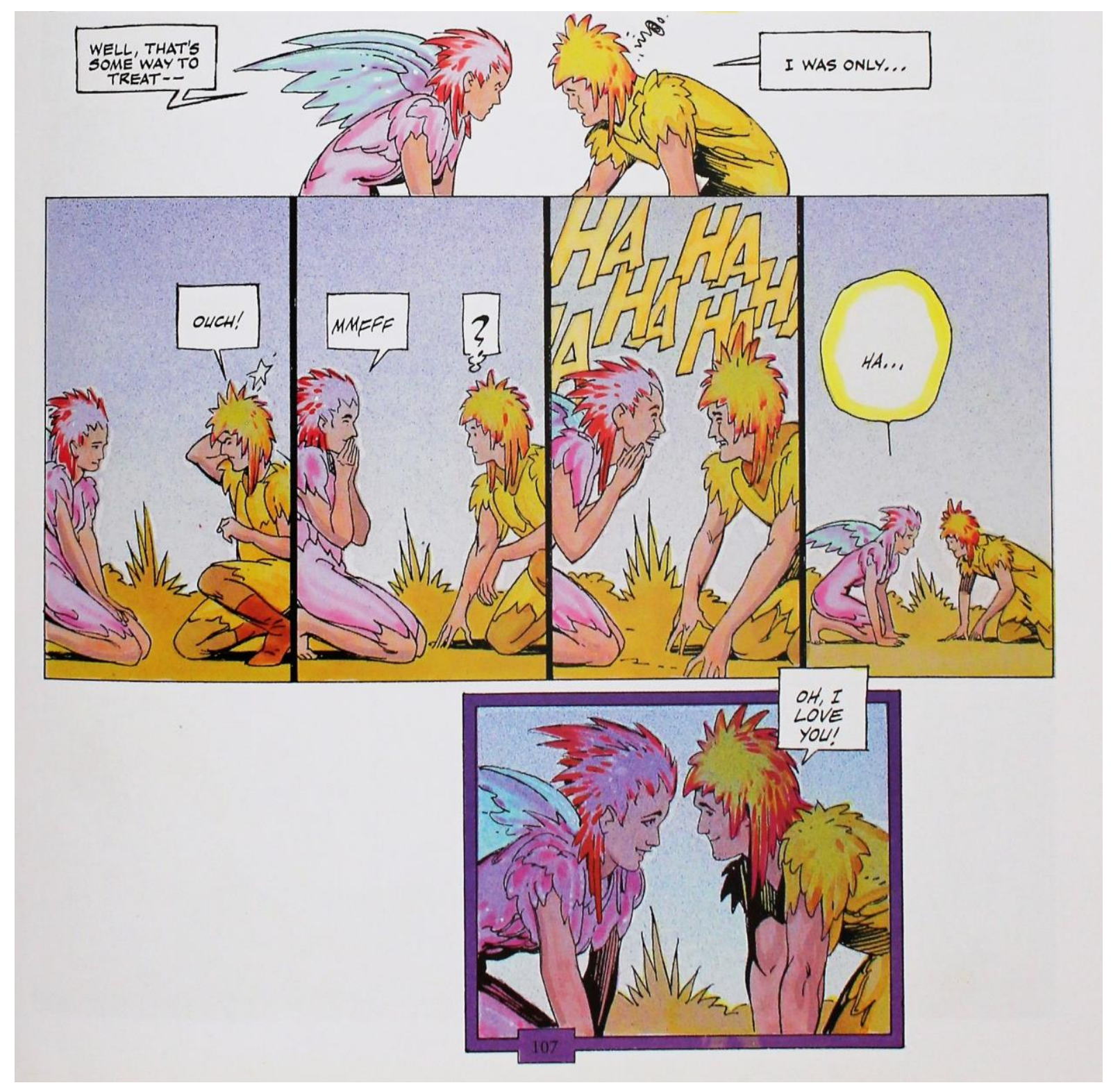

Figure 2: The Papagena/Papageno duet, The Magic Flute, The P. Craig Russell Library of Opera Adaptations Vol. 1, page 103. (C) 1990 P. Craig Russell. Available from NBM Graphic Novels: www.nbmpub.com.

As an opera which has musical elements within the narrative; the eponymous magic flute, and Papageno's magic bells, the representation of these instruments, and their music, is particularly important. The flute's music (Figure 3) is shown through a string of notes which follow the structure of a traditional melody: a stream of sound represented as a linear and continuous movement in time. This is seen in a series of five rectangular panels, the first four of which show movement through a single scene (Russell 2003: 213). Tamino plays his flute, and the music flows through each of the four panels up to a final, single note. The passage of 
time is shown through the receding figure of Tamino, and the procession of the woodland creatures that are following him. In contrast, Papageno's bells are represented by bubbles of individual notes floating in the air. The individual bells form individual notes that jumble together on the page. The note-bubbles representing the bell sounds are irregularly sized, spaced and placed, hinting towards volume, pitch and tempo through their size and position on the page; the larger bubbles suggesting the louder sounds, the higher on the page the higher in pitch, and the left to right spacing the time at which the bell was struck (Russell 2003: 39). While these representations are not accurate transcriptions of the music in a notational sense, they allude to the form of the sound in a way that distinguishes between two distinct types of instrumentation: the flute and the bell.
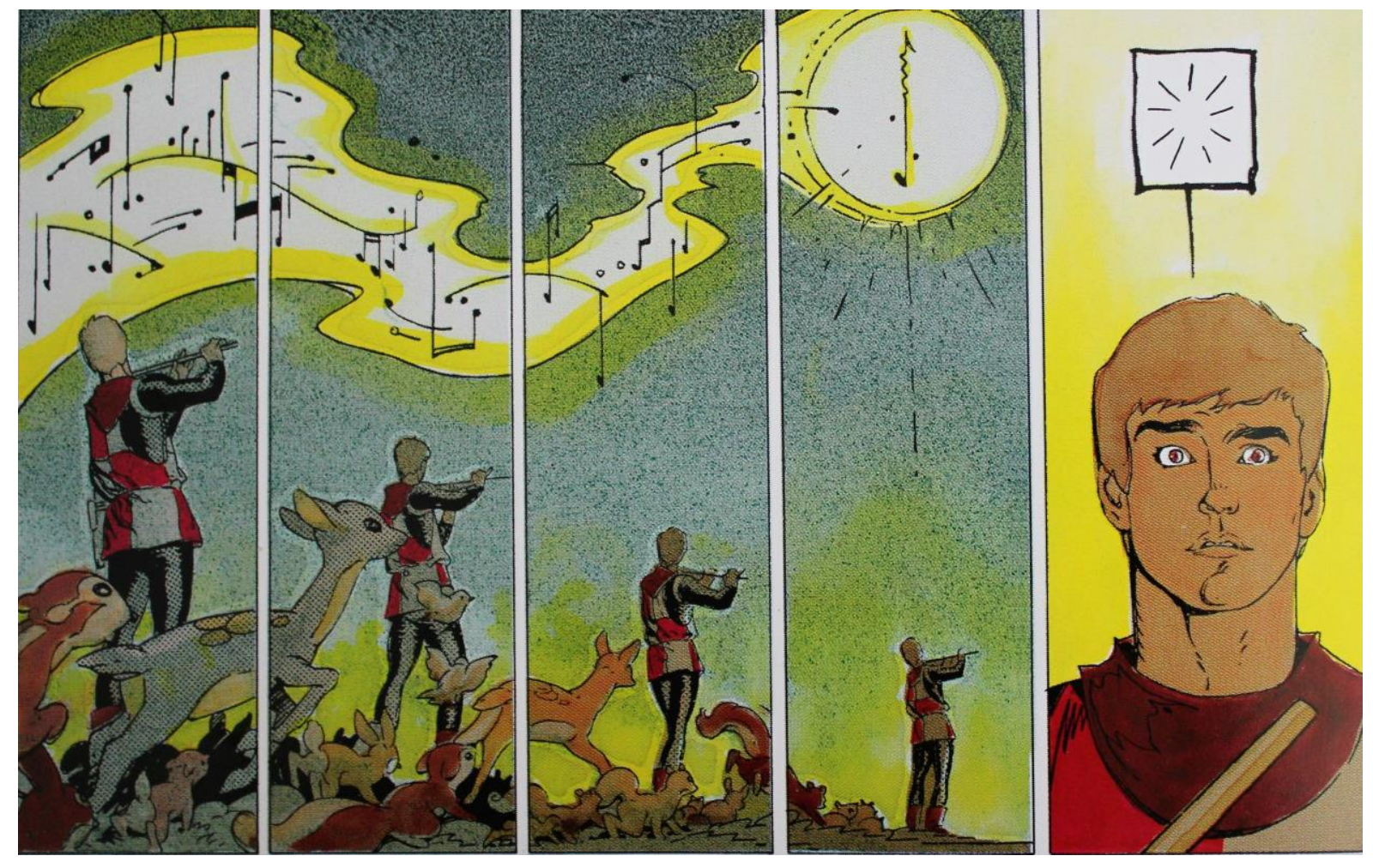

Figure 3: Magic flute, The Magic Flute, The P. Craig Russell Library of Opera Adaptations Vol. 1, page 213. (C) 1990 P. Craig Russell. Available from NBM Graphic Novels: www.nbmpub.com.

Many of the techniques Russell used in The Magic Flute were established within his earlier opera adaptations, one of the most successful of which being his adaptation of Richard Strauss' Salomé. Salomé is the story of an innocent young princess, and her descent into 
madness following her rejection by the prisoner Jokanaan (John the Baptist). Russell's adaptation is illustrated using a vibrant colour palette, juxtaposed images, and unusual angles, which come together to reflect the experimentation of Strauss's early modernist opera, itself based on the scandalous play by Oscar Wilde. Russell draws on the heavy symbolism of Wilde's original play, and the motivic structures of Strauss's later work, while shaping the narrative to suit his own style, and the limitations and possibilities of his medium. That Russell cites instances where the construction of Strauss's opera had a direct impact on his artistic choices (Russell 1991: 48), makes this perhaps his most important adaptation from the perspective of musicalization. Interestingly, it is also in Salomé that we see greater levels of confidence and creative risk-taking.

The dominant recurring images in Russell's Salomé are both taken from the original story as found in Wilde's play, images which are also central to the staging of Strauss' opera, namely the moon, and the 'gaze' as enacted through the various characters of the drama. The thematic relevance of these images is asserted from the first page, where the titles are spelled out over a moonlit sky, and the gaze of Salomé's lust filled step father follows her out of the hedonistic celebrations in the palace (Russell 2004: 108). The centralization of these images is underpinned by a discussion between two palace guards, who reflect on the way the moon looks, 'like a woman rising from a tomb' (2004: 110), asserting the symbolic ties between the moon, and a mystical or dangerous femininity. It is during this same conversation that the dangers of the gaze are also brought to our attention: 'you are always looking at her. You look at her too much. It is dangerous to look at people in such a fashion. Something terrible may happen' (2004: 110). These words of course prove to be prophetic.

The repeated instances of 'looking' in the sense of amorous intent, converge most tragically in Salomé's insatiable desire to look upon the face of Jokanaan. The intensity in this gaze is foregrounded in Russell's work by the similarly constituted pages that bookend 
Salomé's interaction with the holy prisoner $(2004: 116,122)$. In the first of these pages

(Figure 4), the panels are rendered across the full width of the grid, with each panel getting shorter and shorter as we get closer and closer to Salomé's face: the final panel becoming a thin letterbox offering a close up view of Salomé's enraptured eyes as she awaits the sight of this man hidden within the cistern. After their meeting, and Jokanaan’s rejection of Salomé's pleas of: 'let me kiss thy mouth' (2004: 121), there is a similarly constituted page made up of full-width panels, gradually decreasing in height and another close up image of Salomé's gaze, but this time focused in on a single eye. The criss-crossing of the cistern's grid reflected in Salomé's pupil symbolizes her imprisonment to the fate she sealed in gazing upon the holy man. This symbol is later reprised in the representation of Jokanaan's head on the silver platter, which contains the suggestion of an eye (2004: 134).

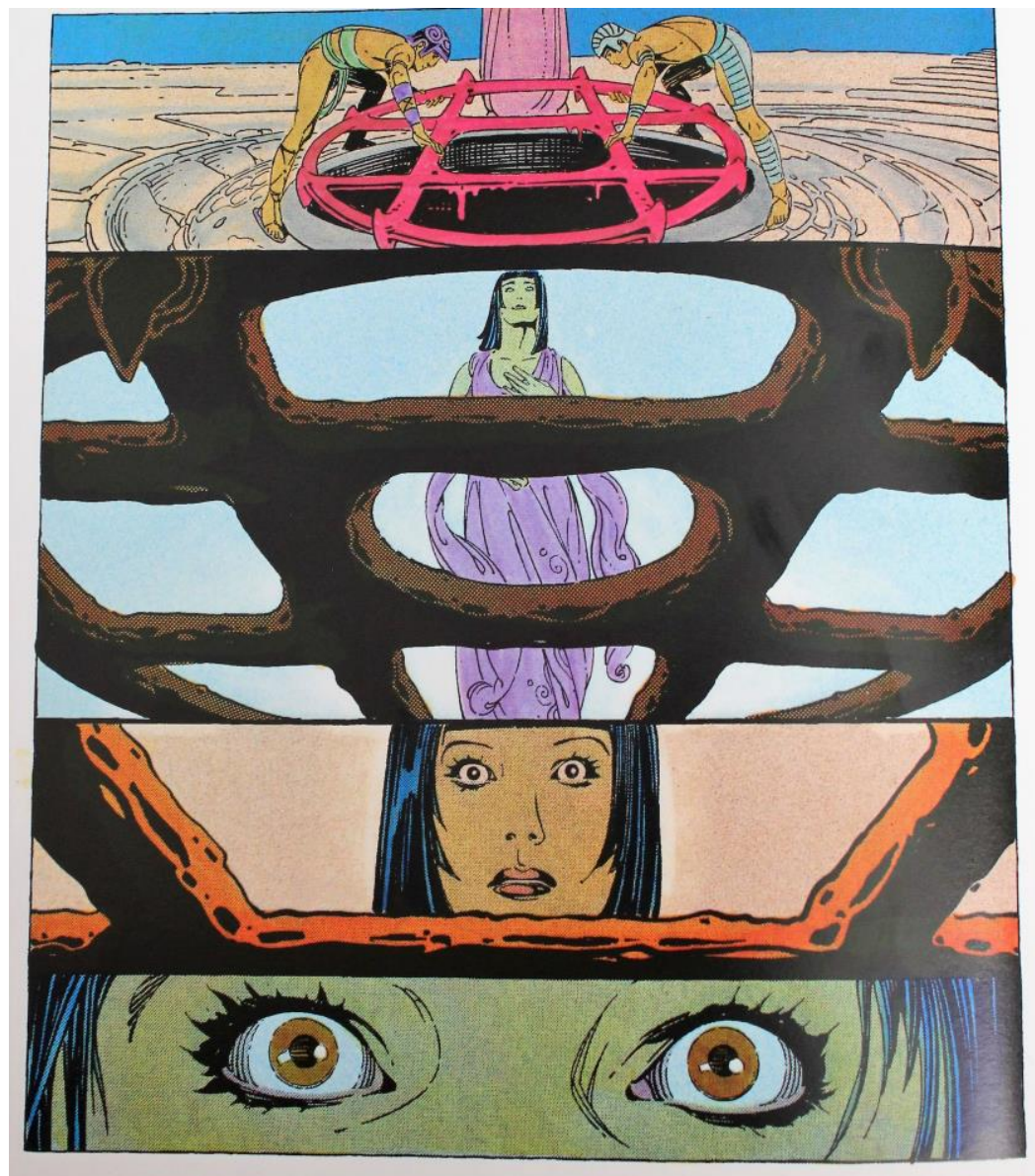

Figure 4: Salomé looks down into the cistern, Salomé, P. Craig Russell's Library of Opera Adaptations Vol. 3, page 116. (C) 1986 P. Craig Russell. Available from NBM Graphic Novels: www.nbmpub.com. 
The moon as a symbol is inextricably tied to Salomé herself, to her femininity and to the fatal aspect of her sexual awakening. It is interesting therefore that it gets interpreted differently by different characters; for the palace guard, it evokes images of death, for King Herod, it is 'like a mad woman who is seeking everywhere for lovers... I am sure she is looking for lovers. Does she not reel like a drunken woman?' (2004: 123), and for the innocent Salomé of the opening pages, the moon is 'cold and chaste. I am sure she is a virgin. Yes she is a virgin. She has never defiled herself. She has never defiled herself to men, like the other goddesses' (2004: 114). As in the original source text (Wilde's play), the moon in Russell's adaptation acts as a mirror, reflecting the attitudes of the characters back on themselves (Russell 1991: 56). For the guard who has a forbidden love for the princess, the moon is death; for the lascivious Herod, it is sexually predatory; and for the innocent Salomé, it is a symbol of purity. Besides what these multiple perspectives reveal about attitudes towards the female, they allow Russell to exploit the shifting symbolism of the moon across his adaptation. These modulated repetitions can be related back to the self-referential meanings Werner Wolf observes within musical form (1999: 23), repetitions that Strauss's opera relies heavily upon in his character motifs and dramatic keys (Murphy 1989: 215).

There are three further explicit examples of musicalization in Russell's Salomé; the moment when Salomé peers down the cistern into the darkness below, her dance of the seven veils, and the grotesque climax of the piece, wherein Salomé descends finally into madness, each of which I will look at more closely in turn. First, as Salomé peers down into the darkness of the cistern housing Jokanaan, she exclaims, 'it must be terrible to be in so black a hole! It is like a tomb [...]' (Russell 2004: 115). This is figured in Strauss's opera through what has been described as a complete blackness of sound (Pruett 2007: 130), a moment that Russell captures in the dark central panel of the page (2004: 115). The page as a whole is a strong example of where a non-sequential reading of the panels takes precedence over the 
sequential narrative. As readers, our eyes are immediately drawn to the blacked out central panel, creating a sense of that descent into darkness. It is only after we have taken in that moment that we return to the sequential story. The translinear aspect of reading comics is, in this instance, not linked to simultaneity as in the earlier example from Neil Gaiman's Sandman Overture. This example disrupts the sequential reading not by evoking a sense of polyphony, but by drawing attention to a later moment, which is then anticipated as we return to a sequential reading. While music cannot create a sense of the past, or of the future, it can build anticipation (Wolf 1999: 25), for example, through a gradual build-up of sound, or through the subtle inclusion of an established motif at a specific moment. The placement of eye-catching panels within a graphic narrative achieves this same effect.

The second musicalized moment in Russell's Salomé is the infamous dance of the seven veils, which lasts some seven minutes in a typical performance of Strauss's opera. This section is adapted across three wordless pages in Russell's work; a purely visual element within the graphic narrative (Figure 5). As Russell himself explains:

I planned to have it work as a visual element in the story and make it almost a visual dance, not a literal dance of drawing her dancing, but having the panel work as such that it stood out in the way that the dance in the opera stands out clearly. (1991: 56)

The dance is coloured in a mix of hot reds, oranges, and yellows, while the simultaneous narrative of the dead palace guard being lifted away and thrown over the walls is contrasted in cool, blue tones (2004: 129). The intermingling visuals of the body of the falling guard, and the dropping of another of Salomé's veils throws each of the events into relief: a combination unique to Russell's rendering. The carnality and animalism of the dance is shown through a close up of Salomé's feet, dancing through the guard's blood as her stepfather wantonly caresses one of her fallen veils. There is death, danger and violence in the image of a guard's axe, which in catching one of the discarded veils offers a clever juxtaposition between the curved lines of the veil, symbolizing the curves of Salomé's body, 
and the hard, glistening edge of the sharpened blade. The final page of the sequence sees

Salomé casting off her remaining veil above Jokanaan's cistern, her silhouette framed against the backdrop of the moon, before she collapses, naked, at her stepfather's feet.

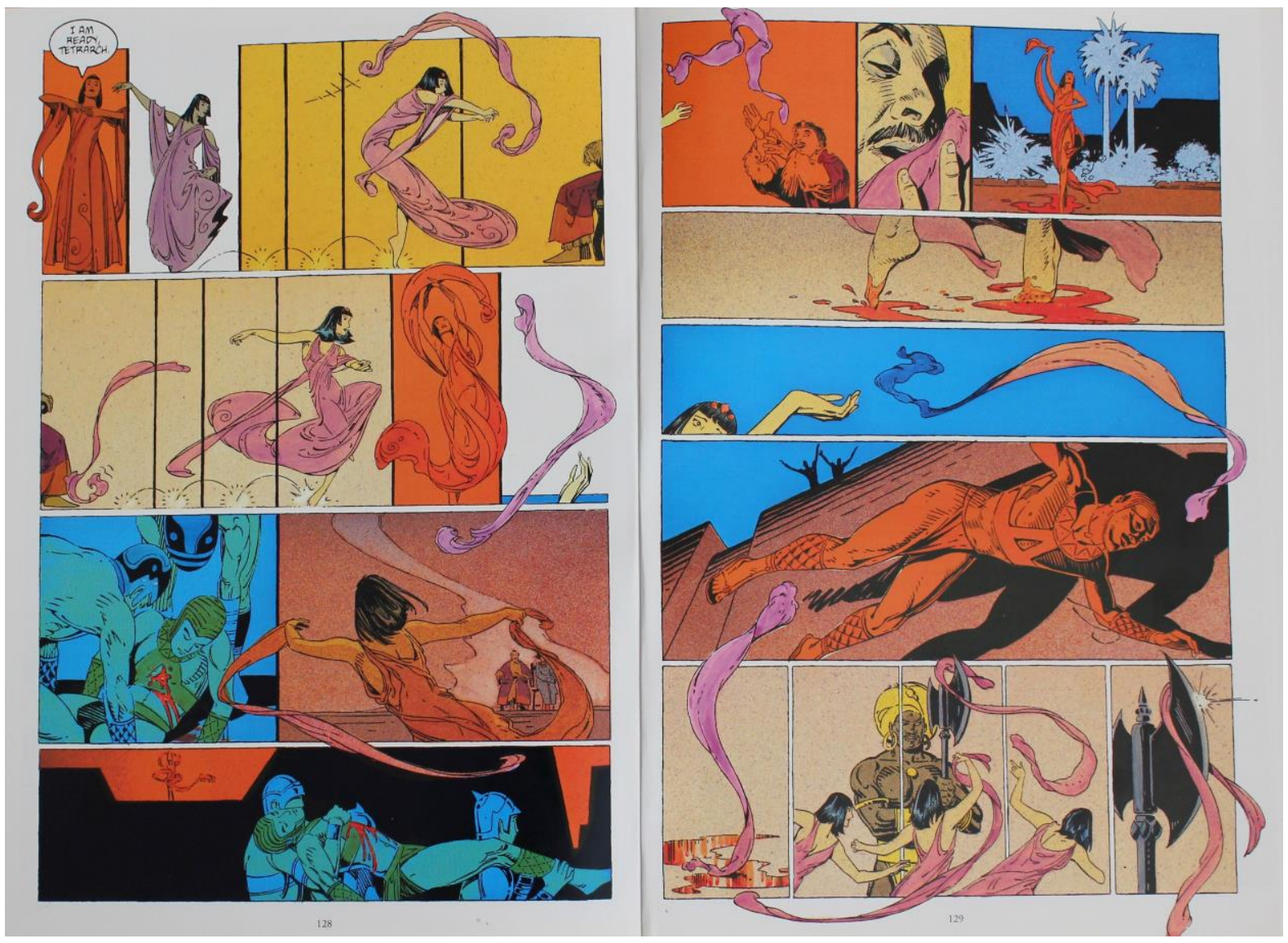

Figure 5: The Dance of the Seven Veils, Salomé, P. Craig Russell's Library of Opera Adaptations Vol. 3, pages 129-30. () 1986 P. Craig Russell. Available from NBM Graphic Novels: www.nbmpub.com.

The arrangement of the panels throughout these dramatic pages hints towards a sense of rhythm and musicality. This begins with the initial sequence of hops that Salomé takes through several thin panels, as the dance begins, and evolves into the flourishes of the veils as they fall freeform across the page. Throughout this section, the panels vary in width and number, extending and compressing the action of the sequence in a way that reflects the dynamism of Strauss' opera. Hannah Miodrag has observed that while reading pace is 'most clearly manipulated by the dimensions and frequency of the panels, $[\ldots]$ story time is more specifically controlled by the way the depicted action is broken down across a sequence' 
(2013: 122). Russell capitalizes on this distinction to create an engaging rendering of this particular sequence in the relatively short space that is more suited to the graphic medium. He contrasts larger, wider panels representing narrative moments, such as the disposal of the guard's body, or moments of particular symbolic or semantic significance, such as the instances capturing Herod's lascivious gaze, with more closely spaced panels that depict the nature of the dance itself. This gives a sense of the movement and rhythm of the dance, while suggesting the longer period of narrative time the dance inhabits.

The final 'musicalized' moment in this adaptation comes at the end, following on from Salomé's kiss with the severed head of Jokanaan. The kiss is rendered in extreme close up in a large central panel. An inversion of the romantic close up, 'so close, in fact, that one cannot tell that Jokanaan's head is disembodied' (Calico et al. 2015: 300), the image confronts the reader with the horror of the moment. After this terrible kiss, Salomé descends into madness. In Strauss' opera this is where the music builds to a dramatic climax, ending with a cadence that incorporates one very dissonant and unorthodox chord. This single chord has been dubbed 'the most sickening chord in all opera', an 'epoch-making dissonance with which Strauss takes Salomé [...] to the depth of degradation', and 'the quintessence of Decadence: here is ecstasy falling in upon itself, crumbling into the abyss' (Ayrey 1989: 124). Speaking of this moment, Russell states that there was, "no way I could capture what Strauss did in the music at that point but I tried to take a clue from it, which is this total disillusion of everything'. He achieved this 'visual approximation of her emotional state' through his depiction of the floor literally falling away beneath her feet (1991: 56). The panel that represents this chord brings together the moonbeams from the dramatic staging of the work, the final fatal symbolism of the moon itself, and Russell's own interpretive choices, to draw the graphic narrative to a dramatic close (Figure 6). 


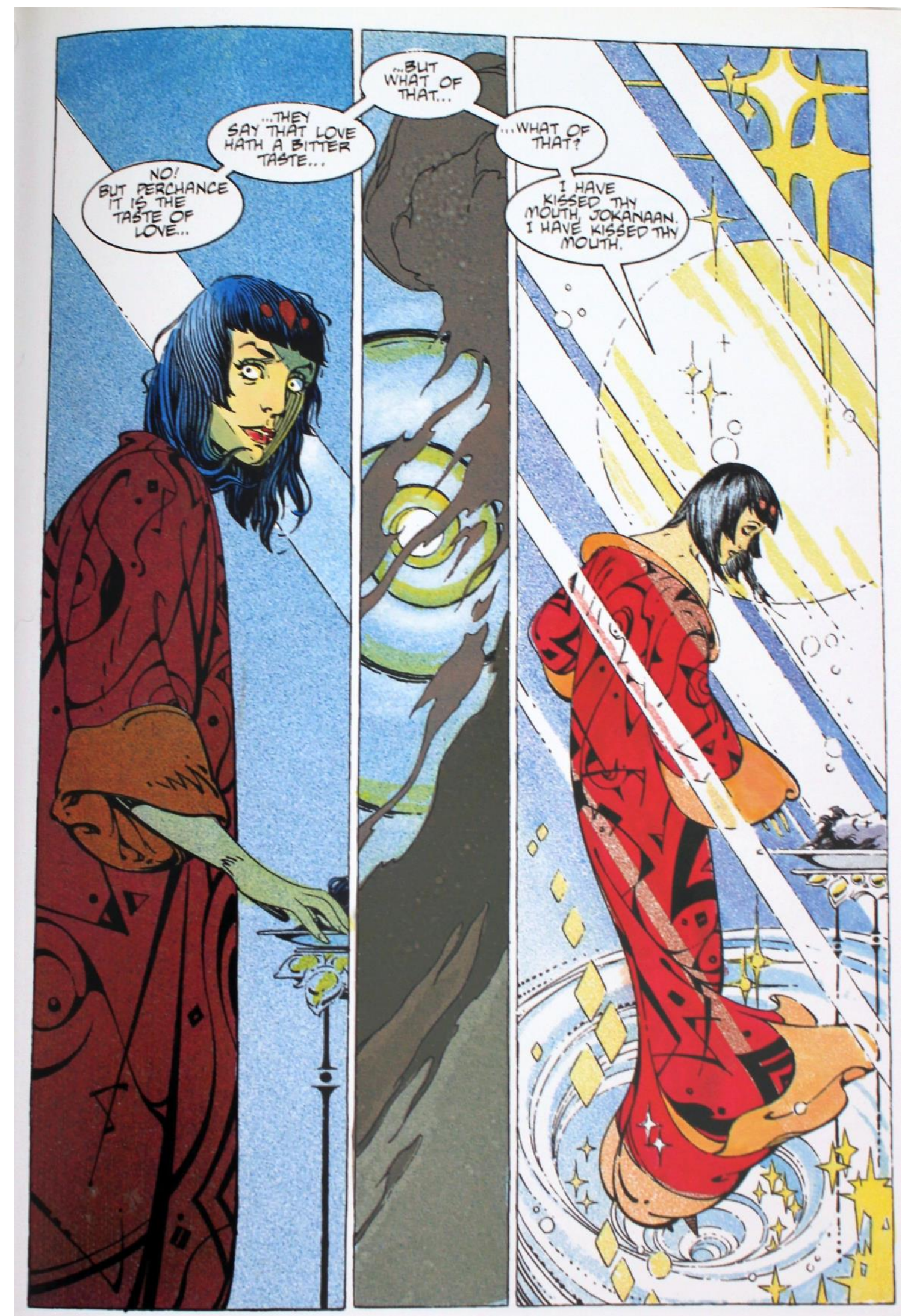

Figure 6: Salomé descends into madness, Salomé, P. Craig Russell's Library of Opera Adaptations Vol. 3, page 139. (C) 1986 P. Craig Russell. Available from NBM Graphic Novels: www.nbmpub.com. 
The significance of Russell's Salomé to the relationship between music and comics extends beyond the graphic narrative itself. In 2014, Table Top Opera (TTO) put together a production of Salomé, which paired a chamber version of Strauss' opera with live dance, and images from P. Craig Russell's adaptation. This production followed on from the success of Pelléas Redux, a production of Claude Debussy's opera Pelléas et Mélisande by the same company in 2012, which likewise paired the music of the opera with images from P. Craig Russell. As Calico et al. state in their review of TTO's Salomé, 'animated cartoons with a figurative aesthetic are increasingly finding their way into opera' (2015: 299). This growing sense of openness and curiosity towards other media within the opera community raises a number of questions regarding the possible influence of comics on the world of music, not least, the question of whether music can be created from a graphic narrative. We already have possible examples of this phenomenon in the soundtracks that accompany graphic narrative to film adaptations, but independent pieces of music drawn from comic book sources have yet to be popularized. How, for example, would the dirge that accompanies the slow procession of Dream's funeral at the close of the original Sandman sound? Could you construct a piece inspired by the whole series? Perhaps an opera, or a ballet? The possibilities for cross-pollination between music and comics are very much in their infancy, but what is clear is that P. Craig Russell's opera adaptations are at the forefront of these exchanges on both sides.

Russell's graphic operas utilize the full range of the medium's techniques and devices to convey their musical source texts in new and interesting ways. As well as drawing on the themes and motivations of the original works, Russell's adaptations take some liberties with the original content, particularly in regards to condensing the time frame of these works, displaying confidence in the comics medium as a vehicle for musical representation. Through uses of symbolism, visual motifs, invocations of the rhythmic pulse of the panels and 
figurative representations of diegetic music, Russell is able to bring out the musicality inherent within comics art, and to demonstrate its potential for musicalization. P. Craig Russell's trailblazing work in translating music into rich, complex graphic narratives, capitalizes on the formal parallels between music and comics in a way that showcases the versatility of the medium.

\section{Conclusion}

Bringing together music and comics through a discussion of form is a natural step from recognizing the wide-ranging representations of music enjoyed by readers of comics in all genres. Music is a huge part of a wider creative culture to which comics belong, and whether it is musical notes issuing from a radio, popular song lyrics appearing in a text, instruments being played, or musicians forming the focus of the story itself, music has been a part of comics, however inconspicuously, for decades. The potential for the musicalization of graphic narratives opens up creative possibilities for artists and writers to see beyond the idea of music as simply a soundtrack, and to embrace new and exciting ways of integrating music and musical intertextuality into the very fabric of their work. Music can be represented in graphic novels both diegetically, through images of musical notation and instrumentation, and through the adaptation of existing music into the visual-textual stream. The advantages of comics as a medium for the production of musicalized narratives encapsulate not only the affinities between music and literature, and between music and visual art, but also mediumspecific properties, such as the potential to express a sense of simultaneity or anticipation through non-sequential reading, to express a sense of rhythm through the arrangement of panels on the page, to represent harmony and/or dissonance through sudden changes in colour or artistic style, and to achieve a sense of sound through grammatextuality and line work. While this article has focused on opera; itself a mixed medium which draws on music, narrative and staging, the techniques used to translate these works into graphic narratives may 
also be used to convey instrumental, or 'absolute' music. The ways in which these representations may differ from opera (or ballet) as mixed media, offer a potential avenue for further study within this largely underresearched area of comics studies: an area which I hope to see crystallizing in future years.

\section{References}

Albers, J. ([1963] 2006), Interaction of Color, New Haven: Yale University Press.

Ayrey, C. (1989), 'Salomé's final monologue', in Derrick Puffett (ed.), Richard Strauss, Salomé, Cambridge: Cambridge University Press, pp. 123-30.

Baetens, J. and Frey, H. (2015), The Graphic Novel: An Introduction, Cambridge: Cambridge University Press.

Brown, K. M. (2013), 'Musical sequences in comics', The Comics Grid: Journal of Comics Scholarship, 3:1, http://doi.org/10.5334/cg.aj. Accessed 24 May 2017.

Calico, Joy H., Homerin, Th. Emil and Brown, Matthew (2015), 'Comic book opera: P. Craig Russell's Salomé in a production by Table Top Opera', The Opera Quarterly, 31:4, pp. 289307.

Carney, S. (2006), 'The tides of history: Alan Moore's historiographic vision', ImageText: Interdisciplinary Comics Studies, 2:2, n.pag.

Eco, U. ([1975] 1976), A Theory of Semiotics, London: Indiana University Press.

Eisner, W. (1985), Comics and Sequential Art, Florida: Poorhouse Press.

Fresnault-Deruelle, P. (1976), 'Du Lineaire au Tabulaire', Communications, 24, pp. 7-23.

Gaiman, N. (2014), Sandman Overture \#2, New York: DC.

Galeyev, B. M. (2007), 'The nature and functions of synesthesia in music', Leonardo, 40:3, pp. 285-88.

Godek, T. (2006), 'Music and comics: Two great tastes that taste great together?', Comix Talk, http://comixtalk.com/music_and_comics_two_great_tastes taste_great together/. Accessed 24 May 2017.

Groensteen, T. (2006), The System of Comics, Jackson: University Press of Mississippi. Hutcheon, L. (2013), A Theory of Adaptation, New York: Routledge..

Lefèvre, P. (2007), 'Incompatible visual ontologies: The problematic adaptation of drawn images', in I. Gordon, M. Jancovich and M. McAllister (eds), Film and Comic Books, Jackson: University of Mississippi, pp. 1-12.

McCloud, S. ([1993] 2001), Understanding Comics: The Invisible Art, New York: Harper Perennial. 
Miodrag, H. (2013), Comics and Language: Reimagining Critical Discourse on the Form, Jackson: University Press of Mississippi.

Mitchell, W. J. T. (2009), 'Beyond comparison', in J. Heer and K. Worcester (eds), A Comics Studies Reader, Jackson: University Press of Mississippi, pp. 116-23.

Moore, A. (2005), V for Vendetta, vols 1-10, New York: DC.

Moore, A. and Gebbie, M. (2006), Lost Girls Book 1, Atlanta: Top Shelf.

Moore, A. and Gibbons, D. (2013), Watchmen: The Deluxe Edition, New York: DC.

Murphy, E. (1989), 'Tonality and form in Salomé', The Music Review, 50:3, pp. 215-30.

O’Malley, B. L. (2004), Scott Pilgrim's Precious Little Life, Portland: Oni Press.

Peters, L. W. (2013), 'Music in Eric Drooker's Flood!', Journal of Graphic Novels and

Comics, 4:2, pp. 332-35, https://doi.org/10.1080/21504857.2012.758164. Accessed 11 May 2017.

Pruett, J. (2007), The Art of P. Craig Russell, Norcross: Desperado.

Russell, P. C. (1991), 'Interview', The Comics Journal, 147, pp. 44-75. (2003), 'The Magic Flute', in The P. Craig Russel Library of Opera Adaptations Vol. 1, New York: NBM. (2004), 'Salomé', in The P. Craig Russel Library of Opera Adaptations Vol. 3, New York: NBM, pp. 107-40. (2014), The Ring of the Nibelung, Milwaukie: Dark Horse.

Spiegelman, A. (2004), 'Picturing a glassy-eyed private I', in P. Karasik and D. Mazzucchelli (eds), Paul Auster, City of Glass, New York: Picador, pp. i-iii.

Whitted, Q. (2011), 'Blues comics', The Hooded Utilitarian, http://www.hoodedutilitarian.com/2011/08/blues-comics/. Accessed 24 May 2017.

Witek, J. (2009), 'The arrow and the grid', in J. Heer and K. Worcester (eds), A Comics Studies Reader, Jackson: University Press of Mississippi, pp. 149-56.

Wolf, W. (1999), The Musicalization of Fiction: A Study in the Theory and History of Intermediality, Atlanta, GA: Rodopi. 